\title{
Distal aortic interventions after repair of ascending dissection: The argument for a more aggressive approach
}

\author{
Eric E. Roselli, MD, ${ }^{a}$ Gabriel Loor, MD, ${ }^{a}$ Jiayan He, ScD, ${ }^{b}$ Aldo E. Rafael, MD, ${ }^{a}$ \\ Jeevanantham Rajeswaran, PhD, ${ }^{\mathrm{b}}$ Penny L. Houghtaling, MS, ${ }^{\mathrm{b}}$ Lars G. Svensson, MD, PhD, ${ }^{\mathrm{a}}$ \\ Eugene H. Blackstone, MD, ${ }^{\mathrm{a}, \mathrm{b}}$ and Bruce W. Lytle, $\mathrm{MD}^{\mathrm{a}}$
}

\begin{abstract}
Objective: Survivors of ascending aortic dissection repair frequently require downstream aortic interventions. Because of a paucity of data, we assessed early and long-term outcomes, and risk factors, of these distal procedures.
\end{abstract}

Methods: From January 1993 to January 2011, 305 patients underwent 429 distal aortic interventions after acute type A (95\% DeBakey type I) dissection repair performed 3.8 years earlier (median); $11 \%$ of interventions used an endovascular approach. Maximum aortic size was $5.9 \pm 1.3 \mathrm{~cm}$. Median follow-up was 3.6 years.

\begin{abstract}
Results: Hospital mortality was $6.1 \%$. Risk factors included graft infection, concomitant coronary artery bypass grafting, combined open arch and descending procedures, and lower distal anastomotic site. Within 10 years, the probability of patients undergoing a reintervention was $38 \%$, with a cumulative incidence of 55 per 100 patients; however, $40(9.3 \%)$ were stage-II elephant trunks. Patients with larger aortic diameters distal to the initial repair, and a stage-I elephant trunk, were more likely to undergo distal interventions. Survival was $65 \%$ at 10 years. Higher body mass index, a longer time between reinterventions, graft infection, combined open arch and descending procedures, and lower distal anastomosis sites were risk factors. The extent of aorta replaced was not associated with increased morbidity or mortality, unless it involved a combined open arch and descending aorta procedure.
\end{abstract}

Conclusions: Distal interventions after ascending aortic dissection repair are feasible, but they are associated with early morbidity and subsequent reinterventions. Rigorous follow-up with early reintervention is important for improving short- and long-term outcomes. An extended hybrid endovascular repair for initial dissection warrants study. (J Thorac Cardiovasc Surg 2015;149:S117-24)

Supplemental material is available online.

From the Department of Thoracic and Cardiovascular Surgery, ${ }^{\mathrm{a}}$ Heart and Vascular Institute, and Department of Quantitative Health Sciences, ${ }^{b}$ Research Institute, Cleveland Clinic, Cleveland, Ohio.

This study was supported in part by the Kenneth Gee and Paula Shaw, $\mathrm{PhD}$, Chair in Heart Research, held by Dr Blackstone. These individuals played no role in the collection of data or analysis or interpretation of the data, and had no right to approve or disapprove publication of the finished article.

Disclosures: Dr Roselli receives speaking honoraria from Vascutek Terumo (Renfrewshire, Scotland, United Kingdom) and Cook Medical (Bloomington, Ind) and is a consultant for Medtronic (Minneapolis, Minn). Dr Svensson holds stock in Posthorax (Winter Park, Fla), ValveXchange (Greenwood Village, Colo), and Cardiosolutions (Stoughton, Mass). All other authors have nothing to disclose with regard to commercial support.

Read at The American Association for Thoracic Surgery Aortic Symposium, New York, New York, April 24-25, 2014.

Received for publication April 24, 2014; revisions received Nov 1, 2014; accepted for publication Nov 7, 2014.

Address for reprints: Eric E. Roselli, MD, Department of Thoracic and Cardiovascular Surgery, Cleveland Clinic, 9500 Euclid Ave/Desk J4-1, Cleveland, OH 44195 (E-mail: roselle@ccf.org).

$0022-5223 / \$ 36.00$

Copyright (C) 2015 by The American Association for Thoracic Surgery

http://dx.doi.org/10.1016/j.jtcvs.2014.11.029
Acute ascending aortic dissection usually extends into the more distal aorta, and survivors of emergency repair often require a subsequent aortic reintervention. ${ }^{1,2}$ These interventions are needed at variable time points, are technically complex, and are often performed as staged procedures at a tertiary care center. New, hybrid techniques to extend dissection repair into the arch and proximal descending aorta have revived debate about the ideal strategy for dealing with acute ascending dissection. ${ }^{3-6}$

Currently, few data are available about outcomes of interventions on the more distal aorta after initial ascending dissection repair, but understanding the risk of later surgery may affect the decision to do a more extensive initial repair. ${ }^{4-10}$ The current study investigates outcomes associated with interventions on the distal aorta in a large cohort of patients who survived an initial ascending aortic dissection repair.

\section{METHODS \\ Patients}

From January 1993 to January 2011, a total of 305 survivors of an initial ascending aortic dissection repair underwent 429 subsequent interventions on the more distal aorta at Cleveland Clinic (Table 1). Patients undergoing reoperation as an isolated root procedure were excluded. The mean 


\section{Abbreviations and Acronyms \\ BMI = body mass index \\ $\mathrm{CABG}=$ coronary artery bypass grafting}

maximum aortic diameter was $5.9 \pm 1.3 \mathrm{~cm}$. The initial aortic dissection was DeBakey type I in $95 \%$ of patients. At initial dissection repair (initial operation), $74 \%$ had ascending aortic replacement; $25 \%$ had arch repair.

\section{Endpoints}

Endpoints were in-hospital morbidity and mortality, short- and longterm all-cause mortality, and short- and long-term freedom from subsequent reinterventions. In-hospital morbidity included stroke, respiratory failure (tracheostomy), prolonged ventilation $(>24 \mathrm{~h})$, renal failure (dialysis), reoperation for bleeding, sepsis, and sternal wound infection. Data were recorded in the Cardiovascular Information Registry at the Cleveland Clinic, a prospectively collected registry of cardiovascular surgery patients that has been maintained for more than 40 years and includes active follow-up. These morbidities follow the definitions in the Society of Thoracic Surgeons National Database (www.sts.org/qualityresearch-patient-safety/quality/quality-performance-measures). In-hospital death and morbidity was used for the acute analysis because many of the patients underwent multiple staged operations, and the interval between stages may have fallen within the 30-day time period.

Systematic follow-up data from the same registry were used to identify all subsequent aortic reinterventions, supplemented with the investigators' review of records, and mortality. The closing date of follow-up was February 1, 2012. Median follow-up was 3.6 years, with 1337 patientyears of data available for analysis. Twenty-five percent of survivors were followed for $>7$ years, and $10 \%$ for $>10$ years.

\section{Segmental Analysis of Aorta}

The extent of aorta repaired was quantified as the number of segments replaced. The site of the proximal or distal anastomosis/landing zone was determined to occur within 1 of 9 segments, based on landmarks: (1) the brachiocephalic artery, (2) the left common carotid artery, (3) the left subclavian artery, (4) the proximal descending, (5) the mid-descending, (6) the supraceliac, (7) the renal, (8) the infrarenal, and (9) the ileofemorals (Figure E1). ${ }^{11}$ The extent of aorta replaced was defined as the difference between the segment numbers at the distal and proximal sites.

\section{Data Analysis}

Analyses were performed using SAS, version 9.2, statistical software (SAS, Inc, Cary, NC).

Risk factors for morbidity and mortality. We assessed inhospital morbidity by combining morbidities, as defined by the Society of Thoracic Surgeons, as a composite event comprising myocardial infarction, tracheostomy, stroke, bleeding, and dialysis. Risk factors for such morbidity were identified using logistic regression, considering the variables in Appendix E1: demographics, symptoms, comorbidities, and procedures performed, including details about the extent of aorta repaired. Variable selection was performed using bootstrap aggregation (bagging) with 500 datasets, and automated, forward, stepwise analysis, retaining variables at $P \leq .05$. $^{12,13}$ Variables appearing in $\geq 50 \%$ of the resulting 500 models were retained as reliably statistically significant. A similar strategy was used to identify risk factors for in-hospital death.

Reinterventions. Time-zero for analysis of reintervention was the time of the first major aortic intervention after an ascending aortic dissection repair (index operation $n=305$ ). All subsequent reinterventions were considered repeated events. The Nelson method was used to nonparametrically estimate the cumulative incidence of reintervention, and a parametric multiphase hazard model was used to obtain parametric estimates for risk factor analysis. ${ }^{14}$

Survival. Nonparametric survival estimates were obtained using the Kaplan-Meier method, and a parametric method was used to resolve the number of phases of instantaneous risk of death (hazard function) and estimate shaping parameters. ${ }^{15}$

Competing-risks analysis. To determine the likelihood of reintervention in the presence of the competing risk of death, we used nested competing-risks methodology. ${ }^{16}$ The instantaneous risk (hazard function) for each competing event was estimated by a parametric method. ${ }^{15}$

Risk factors for subsequent reinterventions and Survival. Time-related effects of patient and procedure variables on subsequent reinterventions were assessed using a modulated renewal methodology that incorporated all patient and procedure variables collected at each subsequent reintervention as time-varying covariables using the multiphase parametric hazard model ${ }^{17}$ Multivariable analysis was performed in the hazard function domain using the variables listed in Appendix E1. Variable selection using bootstrap bagging was performed as described earlier.

Missing values. To account for missing values for some variables, 5-fold multiple imputation was performed ${ }^{18}$ using a Markov-chain Monte Carlo technique employing PROC MI and PROC MIANALYZE.

Presentation. Continuous variables are summarized as mean $\pm \mathrm{SD}$, or as equivalent 15 th, 50 th (median), and 85 th percentiles when data were skewed. Comparisons were made using the Wilcoxon rank sum test for continuous variables, and $\chi^{2}$ analysis for categoric variables. Uncertainty is expressed by $68 \%$ confidence limits, equivalent to \pm 1 standard error.

\section{RESULTS}

The most common indication for the index operation was distal aneurysmal disease $(95 \%) ; 4.6 \%$ of patients had aortic rupture, and 5.9\% had a graft infection (Table 2). Intervention involved the arch in $74 \%$ of cases, and the descending or thoracoabdominal aorta in $37 \%$. Of 112 descending or thoracoabdominal repairs, 35 (31\%) included a stent-graft.

\section{Operative Morbidity and Mortality}

The median postintervention length of stay was 14 days (15th-85th percentiles; range: $8.0-26$ days), and about half that time was spent in the intensive-care unit (median: 95 h; 15th-85th percentiles; range 31-265 days). In-hospital complications associated with all reinterventions $(\mathrm{n}=429)$ included bleeding $(12 \%)$, renal failure requiring dialysis $(4.1 \%)$, tracheostomy $(9.6 \%)$, and myocardial infarction $(0.95 \%)$ (Table 3). Factors associated with increased risk of the composite event included rupture, aneurysmal degeneration, and distal anastomosis below the celiac artery (Table E1).

There were 26 in-hospital deaths (6.1\% of 429$)$. Factors associated with an increased likelihood of early postoperative death included graft infection, combined arch and descending/thoracoabdominal procedure, and coronary artery bypass grafting (CABG; Table E2). Patients who had the fewest aortic segments replaced had a greater likelihood of in-hospital mortality. 
TABLE 1. Baseline characteristics of patients who underwent aortic intervention (index intervention) after initial repair of an ascending aortic dissection (total $\mathbf{n}=\mathbf{3 0 5}$ )

\begin{tabular}{|c|c|c|}
\hline Characteristic & $\mathbf{n}$ & $\begin{array}{l}\text { No. }(\%) \text { or } \\
\text { mean } \pm \text { SD }\end{array}$ \\
\hline Type of dissection & 305 & \\
\hline Type I & & $291(95)$ \\
\hline Type II & & $10(3.3)$ \\
\hline Unknown & & $4(1.3)$ \\
\hline Characteristics of prior operation & 305 & \\
\hline Ascending replacement only & & $122(40)$ \\
\hline Ascending + valve resuspension & & $73(24)$ \\
\hline $\begin{array}{l}\text { Supracoronary ascending }+ \text { aortic } \\
\text { valve replacement }\end{array}$ & & $31(10)$ \\
\hline Bentall & & $69(23)$ \\
\hline Ascending + root valve-sparing & & $10(3.3)$ \\
\hline Characteristics of prior distal anastomosis & 303 & \\
\hline Ascending aorta & & $223(74)$ \\
\hline Arch & & $75(25)$ \\
\hline Descending aorta & & $5(1.7)$ \\
\hline Demographics & 305 & \\
\hline Female & & $75(25)$ \\
\hline Age (y) & 305 & $58 \pm 14$ \\
\hline Height $(\mathrm{cm})$ & 299 & $177 \pm 11$ \\
\hline Body mass index $\left(\mathrm{kg} \cdot \mathrm{m}^{-2}\right)$ & 288 & $28 \pm 5.9$ \\
\hline \multicolumn{3}{|l|}{ Symptoms } \\
\hline NYHA functional class & 299 & \\
\hline I & & $160(54)$ \\
\hline II & & $97(32)$ \\
\hline III & & $30(10)$ \\
\hline IV & & $12(4.0)$ \\
\hline Heart failure & 303 & $42(14)$ \\
\hline \multicolumn{3}{|l|}{ Cardiac comorbidities } \\
\hline Number of previous cardiac operations & 305 & \\
\hline 1 & & $248(81)$ \\
\hline 2 or more & & $57(19)$ \\
\hline Connective tissue disorder & 305 & $61(20)$ \\
\hline Marfan & & $47(77)$ \\
\hline Ehlers-Danlos & & $2(3.3)$ \\
\hline Loeys-Dietz & & $2(3.3)$ \\
\hline Marfanoid & & $10(16)$ \\
\hline Prior myocardial infarction & 305 & $54(18)$ \\
\hline Left ventricular ejection fraction (\%) & 200 & $53 \pm 7.5$ \\
\hline $\begin{array}{l}\text { Number of systems diseased } \\
\quad \text { (stenosis } \geq 50 \% \text { ) }\end{array}$ & 214 & \\
\hline 0 & & $159(74)$ \\
\hline 1 & & $35(16)$ \\
\hline 2 & & $11(5.1)$ \\
\hline 3 & & $9(4.2)$ \\
\hline Endocarditis & 303 & $16(5.3)$ \\
\hline Atrial fibrillation or flutter & 287 & $14(4.9)$ \\
\hline \multicolumn{3}{|l|}{ Noncardiac comorbidities } \\
\hline Peripheral arterial disease & 305 & $49(16)$ \\
\hline Carotid disease & 305 & $79(26)$ \\
\hline Hypertension & 303 & $261(86)$ \\
\hline Diabetes & 295 & \\
\hline
\end{tabular}

TABLE 1. Continued

\begin{tabular}{|c|c|c|}
\hline Characteristic & $\mathbf{n}$ & $\begin{array}{l}\text { No. }(\%) \text { or } \\
\text { mean } \pm \text { SD }\end{array}$ \\
\hline Pharmacologically treated & & $15(5.1)$ \\
\hline Insulin treated & & $3(1.0)$ \\
\hline Chronic obstructive pulmonary disease & 303 & $62(20)$ \\
\hline Renal dialysis & 296 & $4(1.4)$ \\
\hline Prior stroke & 298 & $63(21)$ \\
\hline Creatinine $\left(\mathrm{mg} \cdot \mathrm{dL}^{-1}\right)$ & 303 & $1.1 \pm 0.93$ \\
\hline Hematocrit $(\%)$ & 299 & $36 \pm 6.0$ \\
\hline \multicolumn{3}{|l|}{ Surgical details (index reintervention) } \\
\hline $\begin{array}{l}\text { Interval (y) from initial dissection repair } \\
(15 \mathrm{th} / 50 \mathrm{th} / 85 \text { th percentile })\end{array}$ & 304 & $0.52 / 3.8 / 12$ \\
\hline Number of surgical components & 250 & \\
\hline 1 & & $100(40)$ \\
\hline 2 & & $109(44)$ \\
\hline 3 & & $32(13)$ \\
\hline 4 & & $8(3.2)$ \\
\hline 5 & & $1(0.40)$ \\
\hline \multicolumn{3}{|l|}{ Support } \\
\hline Cardiopulmonary bypass & 305 & $266(87)$ \\
\hline Cardiopulmonary bypass time (min) & 305 & $151 \pm 88$ \\
\hline Circulatory arrest & 305 & $238(78)$ \\
\hline Circulatory arrest time (min) & 305 & $28 \pm 26$ \\
\hline Aortic clamp/balloon occlusion & 305 & $236(77)$ \\
\hline Myocardial ischemic time (min) & 305 & $73 \pm 62$ \\
\hline \multicolumn{3}{|l|}{ Concomitant surgical procedures } \\
\hline Aortic valve surgery & 305 & $96(31)$ \\
\hline Coronary artery bypass grafting & 305 & $35(11)$ \\
\hline
\end{tabular}

\section{Subsequent Reinterventions}

On follow-up computed tomography, 226 of 278 patients $(81 \%)$ had a residual dissection, and the false lumen was patent distal to the repair in 192 of $200(96 \%)$ of those. A total of 121 had an elephant trunk first-stage procedure. Of these, $33 \%$ had a second-stage procedure; in $7 \%$, it was completed endovascularly, and $9 \%$ died before the second stage. Fifty-seven percent were either lost to follow-up or did not have a reintervention (first stage done prophylactically or patient refused treatment).

Among 305 patients, 110 had 124 subsequent reinterventions (Figure 1). The cumulative number of reinterventions per 100 patients was 30 , by 1 year, and 55 , by 10 years (Figure 2). The risk of reintervention peaked at around 3 months and then was constant at 2 reinterventions/ 100 years (Figure E2).

Patients who underwent first-stage elephant trunk procedures had a high risk of reintervention within the first year; those with larger postoperative aortic diameter distal to the index repair had a higher risk of both early and late reintervention (Table 4; and Figure E3). The number of interventions was not associated with the risk of subsequent interventions. More segments replaced, 
TABLE 2. Details of the index aortic intervention after initial repair of acute dissection (total $\mathbf{n}=\mathbf{3 0 5}$ )

\begin{tabular}{|c|c|c|}
\hline Variable & $\mathbf{n}$ & No. $(\%)$ or mean \pm SD \\
\hline Indication for intervention & 305 & \\
\hline Aneurysmal degeneration & & $280(92)$ \\
\hline Infected graft & & $18(5.9)$ \\
\hline Symptomatic chronic dissection & & $27(8.9)$ \\
\hline New dissection & & $14(4.6)$ \\
\hline Rupture & & $14(4.6)$ \\
\hline Other & & $26(8.5)$ \\
\hline Distal extent of dissection & 277 & \\
\hline Thoracic & & $42(15)$ \\
\hline Abdominal/visceral & & $87(31)$ \\
\hline Ileofemoral & & $148(53)$ \\
\hline False lumen patent & 286 & $268(94)$ \\
\hline \multicolumn{3}{|l|}{ Procedure } \\
\hline Ascending aorta repair & 305 & $209(69)$ \\
\hline Elephant trunk repair & 305 & $146(48)$ \\
\hline First stage & & $121(85)$ \\
\hline Second stage & & $10(7.0)$ \\
\hline Frozen & & $12(8.4)$ \\
\hline Missing & & $3(2.0)$ \\
\hline Arch & 305 & $227(74)$ \\
\hline Descending/thoracoabdominal aorta & 305 & $112(37)$ \\
\hline Approach to descending aorta & 112 & \\
\hline Open & & $77(69)$ \\
\hline Endograft stent & & $35(31)$ \\
\hline Site of proximal aortic anastomosis & 304 & \\
\hline Before BCA & & 217 (71) \\
\hline Between BCA and LCCA & & $4(1.3)$ \\
\hline Between LCCA and LSCA & & $17(5.6)$ \\
\hline After LSCA & & $66(22)$ \\
\hline Site of distal aortic anastomosis & 303 & \\
\hline Before BCA & & $10(3.3)$ \\
\hline Between BCA and LCCA & & $23(7.6)$ \\
\hline Between LCCA and LSCA & & $55(18)$ \\
\hline After LSCA & & $117(39)$ \\
\hline Mid-descending & & $48(16)$ \\
\hline Supraceliac & & $27(8.9)$ \\
\hline Renal & & $11(3.6)$ \\
\hline Infrarenal & & $9(3.0)$ \\
\hline Ileofemoral & & $3(0.99)$ \\
\hline Segment value: extent of aorta replaced & 303 & \\
\hline 0 & & $11(3.6)$ \\
\hline 1 & & $54(18)$ \\
\hline 2 & & $80(26)$ \\
\hline 3 & & $133(44)$ \\
\hline 4 & & $16(5.3)$ \\
\hline 5 & & $6(2.0)$ \\
\hline 6 & & $1(0.33)$ \\
\hline 7 & & $1(0.33)$ \\
\hline 8 & & $1(0.33)$ \\
\hline Aorta size $(\mathrm{cm})$ & 292 & $5.9 \pm 1.3$ \\
\hline Aortic diameter distal to repair $(\mathrm{cm})$ & 278 & $4.6 \pm 1.5$ \\
\hline
\end{tabular}

higher distal anastomosis sites, and arch procedures were associated with a higher risk of reintervention univariably, but not after accounting for other risk factors $(P>.30)$.

\section{Survival}

Risk of mortality was high for the first 3 months after surgery and then declined to a constant risk (Figure E4). Unadjusted survival at 30 days, at 6 months, and at 1, 3, 5,7 , and 10 years was $92 \%, 88 \%, 84 \%, 77 \%, 73 \%$, $67 \%$, and $65 \%$, respectively (Figure 3 ).

Graft infection, concomitant CABG, and larger body mass index (BMI) were incremental risk factors for early death (Table 5). Combined arch and descending/ thoracoabdominal procedures (Figure E5), a lower distal anastomosis site, and a longer interval between interventions were also associated with increased early death.

The effect of BMI differed in the early versus late phases. Increased mortality was associated with higher BMI in the early phase, but with lower BMI in the late phase. First-stage elephant trunk procedures and lower creatinine clearance were associated with reduced late-phase survival. The extent of aorta replaced was not associated with reduced long-term survival (Figure E6), nor was number of prior interventions.

\section{Competing-Risks Analysis}

Among 305 patients who had an index intervention after ascending dissection repair, 110 had a first subsequent reintervention, and 68 died without another intervention; 13 of 110 had a second reintervention, and 19 of 110 died without another intervention (Figure 1). By 10 years, the chance of a first reintervention was $38 \%$, and the chance of dying without another intervention was $28 \%$ (Figure 4).

\section{DISCUSSION}

Improved management of acute and chronic dissections has led to reduced acute mortality and increased longterm survival. Among patients surviving ascending dissection repair, $9 \%$ to $67 \%$ will require a second aortic intervention within 10 years. ${ }^{1,2,10,19}$

\section{Outcomes Associated With Aortic Intervention in Survivors of Acute Dissection}

Few data are available about reinterventions on the downstream aorta in survivors of ascending dissection repair. Halstead and colleagues ${ }^{7}$ reoperated on 25 of 179 patients after acute type A aortic dissection and found that reoperations were not associated with decreased survival. Estrera and colleagues ${ }^{9}$ reported a 5-year survival of $80 \%$ in 104 patients who underwent reoperations on the proximal aorta after previous aneurysm repair. Pugliese 
TABLE 3. Operative morbidity and mortality after intervention following initial repair of an ascending aortic dissection

\begin{tabular}{|c|c|c|c|c|}
\hline \multirow[b]{2}{*}{ Complication } & \multicolumn{2}{|c|}{ First (index) intervention $(n=305)$} & \multicolumn{2}{|c|}{ All interventions $(n=429)$} \\
\hline & $\mathbf{n}$ & No. $(\%)[68 \%$ CLs $]$ & $\mathbf{n}$ & No. $(\%)[68 \%$ CLs $]$ \\
\hline In-hospital death & 305 & $25(8.2)[6.6-10]$ & 429 & $26(6.1)[4.9-7.4]$ \\
\hline Morbidity composite & 305 & 77 (25) [23-28] & 429 & 95 (22) [20-24] \\
\hline Bleeding & 305 & 42 (14) [12-16] & 429 & $51(12)[10-14]$ \\
\hline Stroke & 305 & $14(4.6)[3.4-6.1]$ & 423 & $17(4.0)[3.0-5.2]$ \\
\hline Renal failure requiring dialysis & 294 & $15(5.1)[3.8-6.7]$ & 411 & $17(4.1)[3.1-5.4]$ \\
\hline Renal failure & 305 & 47 (15) [13-18] & 423 & $56(13)[12-15]$ \\
\hline Prolonged ventilation ( $>24$ h) & 266 & $139(52)[49-55]$ & 379 & $198(52)[50-55]$ \\
\hline Tracheostomy & 302 & $33(11)[9.1-13]$ & 426 & $41(9.6)[8.2-11]$ \\
\hline Myocardial infarction & 305 & $4(1.3)[0.69-2.3]$ & 423 & $4(0.95)[0.50-1.7]$ \\
\hline Intra-aortic balloon pump & 305 & 5 (1.6) [0.94-2.7] & 423 & $5(1.2)[0.67-2.0]$ \\
\hline Sepsis & 305 & 15 (4.9) [3.7-6.5] & 423 & $17(4.0)[3.1-5.2]$ \\
\hline Deep sternal wound infection & 305 & $1(0.33)[0.065-1.1]$ & 423 & $1(0.24)[0.040-0.78]$ \\
\hline Atrial fibrillation or flutter & 276 & $43(16)[13-18]$ & 381 & $52(13)[12-16]$ \\
\hline Length of stay (15th/50th/85th percentile) & 305 & & & \\
\hline $\mathrm{ICU}(\mathrm{h})$ & & $43 / 95 / 332$ & & $31 / 95 / 265$ \\
\hline Postoperative (d) & & $8.0 / 14 / 27$ & & $8.0 / 14 / 26$ \\
\hline
\end{tabular}

$\mathrm{n}$ values are for patients with data available. Morbidity composite = bleeding, stroke, dialysis, tracheostomy, and myocardial infarction. $C L$, Confidence limit; $I C U$, intensive-care unit.

and colleagues ${ }^{10}$ found a 5-year survival of $88 \%$ after reoperation on 19 survivors of ascending dissection repair. Based on these studies, surgeons have maintained that interventions after acute dissection repair are safe and justify a conservative strategy at initial operation.

In the current series, in-hospital mortality of $6.1 \%$ was reasonable considering the complexity of cases, and mortality was $8.2 \%$ after the first subsequent reintervention. This mortality reflects the experience at a center with substantial expertise in aortic reoperations. However, there were major morbidities, multiple reinterventions, and low long-term survival, considering the young patient age. Clearly, aortic dissections render patients susceptible to downstream complications, and the aorta is rarely "healed" after an emergency ascending repair. ${ }^{20}$ Competing risks is an important way to think about these patients, because they have chronic disease such that any native aorta is at risk

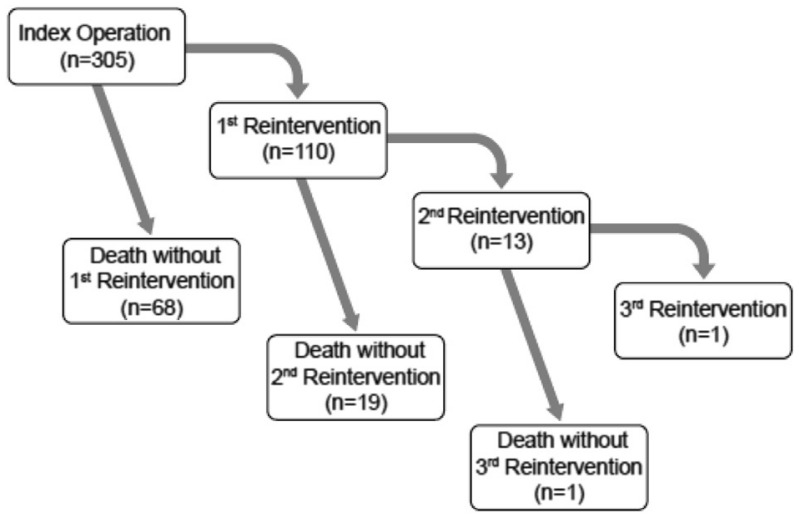

FIGURE 1. Subsequent reinterventions after index operation and the competing risk of death without these reinterventions. for further aneurysmal degeneration or progression of dissection. Survivors are always at risk for reintervention or death associated with those possibilities.

\section{Risk Factors for Mortality}

We found several important risk factors for reduced short- and long-term survival. Patients who presented with graft infections had a 9-fold increase in hospital death and reduced long-term survival. This is consistent with the experience of Dossche and colleagues, ${ }^{21}$ who identified endocarditis and graft infections as independent risk factors for death after aortic reoperation. Most graft infections were

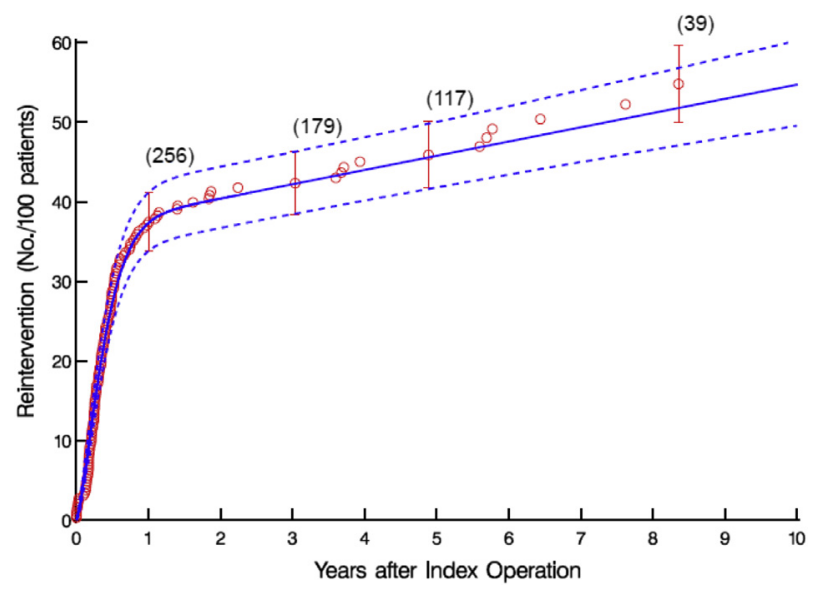

FIGURE 2. Cumulative number of subsequent reinterventions after the index operation. Each circle represents a reintervention; vertical bars show asymmetric $68 \%$ confidence limits equivalent to \pm 1 standard error. The solid line represents parametric estimates of the cumulative number of reinterventions enclosed within a $68 \%$ confidence band. Numbers in parentheses are patients remaining at risk. 
TABLE 4. Incremental risk factors for subsequent reinterventions after index intervention

\begin{tabular}{|c|c|c|c|}
\hline Factor & Estimate $\pm \mathrm{SE}$ & $\boldsymbol{P}$ & Reliability (\%) \\
\hline \multicolumn{4}{|l|}{ Early risk } \\
\hline $\begin{array}{l}\text { Larger predischarge aortic } \\
\text { diameter (distal to repair)* }\end{array}$ & $1.7 \pm 0.53$ & .001 & 64 \\
\hline $\begin{array}{l}\text { Index operation }=\text { first-stage } \\
\text { elephant trunk }\end{array}$ & $2.9 \pm 0.69$ & $<.0001$ & 80 \\
\hline 1 Previous intervention & $-0.036 \pm 0.69$ & $>.9$ & 13 \\
\hline$\geq 2$ Previous interventions & $-0.34 \pm 2.1$ & .9 & 13 \\
\hline \multicolumn{4}{|l|}{ Late risk } \\
\hline $\begin{array}{l}\text { Larger predischarge aortic } \\
\text { diameter (distal to repair)* }\end{array}$ & $3.6 \pm 1.0$ & .001 & 83 \\
\hline 1 Prior intervention & $-0.082 \pm 0.63$ & .9 & 20 \\
\hline
\end{tabular}

treated by excision with only a small segment of adjacent aorta (a segmental value of zero), which may account for the bimodal risk associated with the segmental analysis. Antibiotic prophylaxis and early recognition of infections is critical in patients undergoing dissection repairs. ${ }^{22}$ After aortic dissection repair, patients should be counseled about the importance of antibiotic prophylaxis for invasive procedures.

As expected, myocardial ischemia increases risk. Patients who required concomitant $\mathrm{CABG}$ had an increased risk of early and late death. Physicians should counsel patients who survive an aortic dissection about aggressive risk-factor modification to prevent progression of arteriosclerosis. Similarly, patients with a larger BMI had greater upfront risk. However, once they survived the early hazard phase, patients with a lower BMI had an increased likelihood of death. This increase may be related to the finding that patients with a lower BMI have demonstrated

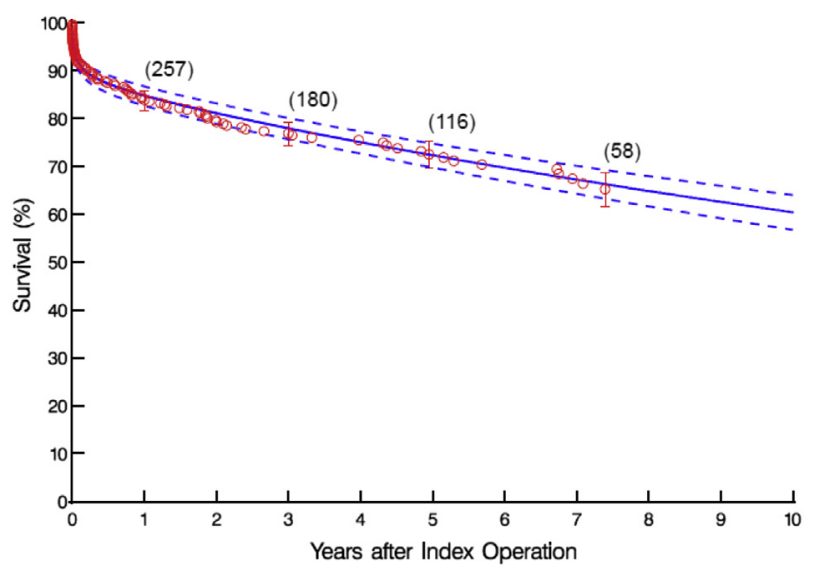

FIGURE 3. Survival after index operation. Each circle represents a death; vertical bars show asymmetric $68 \%$ confidence limits equivalent to \pm 1 standard error. Solid line represents parametric estimates of survival enclosed within a $68 \%$ confidence band. Numbers in parentheses are patients remaining at risk. increased aortic wall tension and associated risk of rupture. ${ }^{23}$ Finally, lower creatinine clearance was a risk factor for long-term mortality and should be considered during follow-up imaging and when risk-stratifying these patients. ${ }^{24,25}$

\section{Type of Intervention and Extent of Repair}

The variety of repair strategies used in this study reflects the complexity of disease and treatment trends. Patients who had a combined arch and descending repair had an 18 times greater risk of in-hospital death and reduced survival than those with a lesser extent of repair. These combined procedures were typically performed through a clamshell incision using circulatory arrest. This approach to isthmus aneurysms occurred earlier in the study period, before adoption of the staged elephant trunk approach. In addition, many of these patients presented with rupture. A staged elephant trunk procedure is now our preferred method for treating these patients. ${ }^{26,27}$ Even in patients presenting with rupture, we will now choose a singlestage frozen elephant trunk procedure over the clamshell approach. $^{28,29}$

Patients who underwent a first-stage elephant trunk after ascending dissection repair had decreased long-term survival and a higher risk of reintervention compared with others, but they did not have a higher acute risk. The need for an elephant trunk procedure in these patients was likely a marker for severity of aortic disease, analogous to those who underwent combined arch and descending repair. Many had either rapid degeneration of multiple aortic segments or presented at a late stage of disease. By contrast, patients who underwent a total arch repair without elephant trunk creation or an isolated descending repair (without arch) likely had disease limited to the segments treated, and consequently, had a better long-term outcome. An elephant trunk should be used when needed for multisegment disease, but when it is needed, it points to a poor prognosis. If a hybrid extended repair can be performed safely at the time of initial dissection, later reinterventions may be less extensive.

Other risk factors for late death included a more downstream site of the distal anastomosis and a longer interval between dissection and reintervention. These associations suggest that patients with more-advanced disease at first reintervention do worse. Extending the repair to involve multiple segments (up to 4) did not affect survival, but neither did the number of reoperations. It has been shown that staging thoracoabdominal aneurysm repairs reduces risk of spinal cord ischemia. ${ }^{30,31}$

\section{Follow-up of Patients Surviving Dissection Repair and Subsequent Major Aortic Intervention}

This study emphasizes the need for aggressive surveillance and early intervention. We recommend a computed 
TABLE 5. Risk factors for early- and late-phase mortality after index intervention

\begin{tabular}{|c|c|c|c|}
\hline Factor & Estimate \pm SE & $P$ & $\begin{array}{c}\text { Reliability } \\
(\%)\end{array}$ \\
\hline \multicolumn{4}{|l|}{ Early risk } \\
\hline $\begin{array}{l}\text { Indication for reoperation: } \\
\text { infected graft }\end{array}$ & $3.6 \pm 0.65$ & $<.001$ & 84 \\
\hline $\begin{array}{l}\text { Combined arch and descending/ } \\
\text { thoracoabdominal procedure }\end{array}$ & $0.87 \pm 0.46$ & .06 & 70 \\
\hline $\begin{array}{l}\text { Longer interval (y) between } \\
\text { aortic surgeries }\end{array}$ & $0.10 \pm 0.027$ & $<.001$ & 72 \\
\hline Larger body mass index* & $0.72 \pm 0.24$ & .003 & 56 \\
\hline Coronary artery bypass grafting & $2.0 \pm 0.57$ & .001 & 43 \\
\hline Lower distal anastomosis site & $2.3 \pm 0.64$ & .001 & 87 \\
\hline 1 Prior reintervention & $-0.58 \pm 0.63$ & .4 & 9 \\
\hline \multicolumn{4}{|l|}{ Late risk } \\
\hline Smaller body mass index & $-0.97 \pm 0.49$ & .05 & 72 \\
\hline First-stage elephant trunk & $2.3 \pm 0.41$ & $<.001$ & 74 \\
\hline Lower creatinine clearance $\dagger$ & $-0.58 \pm 0.24$ & .02 & 58 \\
\hline 1 Prior reintervention & $-0.045 \pm 0.46$ & .9 & 18 \\
\hline$\geq 2$ Prior reinterventions & $-0.22 \pm 1.4$ & .9 & 18 \\
\hline
\end{tabular}

tomography scan of the aorta for all patients who have survived an acute DeBakey type I aortic dissection, before discharge, at 3 months, and annually. Early identification of a distal complication may reduce the risk of a subsequent operation and improve long-term survival. Even after reintervention, continued imaging surveillance is important. We found a persistent risk for reintervention or death even after the first and second interventions. Patients who had a delay between interventions were at greatest risk. Considered together, these findings suggest that survival may be improved by aggressive surveillance and early segmental intervention.

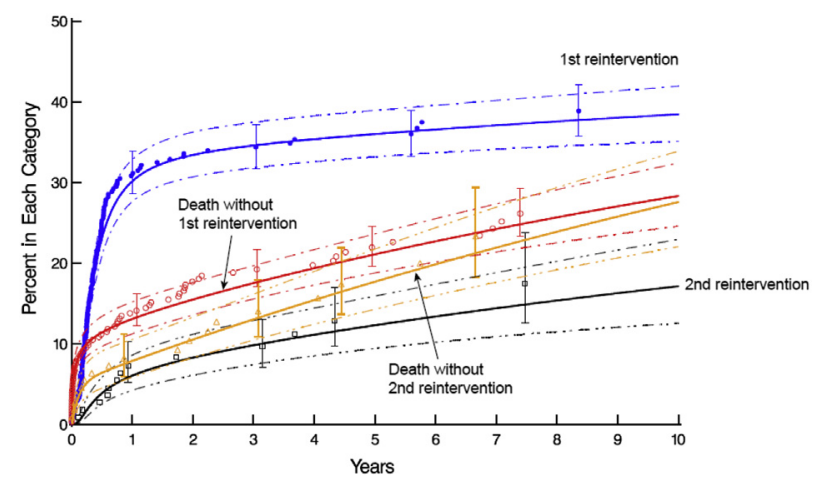

FIGURE 4. Two superimposed competing-risks analyses illustrating the likelihood of occurrence of subsequent reinterventions or interperiod death without reintervention. Horizontal axis restarts at the time of each successive reintervention. Solid lines represent parametric estimates enclosed within dashed $68 \%$ confidence band equivalent to \pm 1 standard error. Symbols are nonparametric estimates with $68 \%$ confidence bars.

\section{Should We Be More Aggressive at Initial Operation?}

The advent of hybrid endovascular repair strategies has revived the debate over how best to treat an acute ascending aortic dissection. The frozen elephant trunk technique is an evolving method for performing extended repair of type A dissection in patients at high risk for late aortic complications. $^{3,32-34}$ Our experience with this approach suggests a modest increase in circulatory arrest times and false lumen thrombosis of $88 \%$. Supporters of a conservative, isolated, ascending repair strategy cite high durability, low risk of reintervention, and good outcomes after reoperation using this approach. ${ }^{1,10}$ However, many of these earlier studies included mixed populations (both DeBakey type I and II dissections), and not all patients were followed routinely, with many deaths attributable to sudden causes (aortic complications may have contributed to these). Aortic reintervention is associated with substantial morbidity and mortality in patients who require both arch and descending repair. Why not remove this risk factor from the equation by addressing any potential pathology of the arch and isthmus at the time of the initial dissection repair? ${ }^{35}$

One could be selective in this approach; better prediction is needed of who will require a subsequent intervention. Some studies have identified risk factors associated with reoperations after repair of acute type A dissections, but few data are available on preoperative findings associated with the need for later reoperation. ${ }^{19,36}$ In addition, there is a need for access to better devices that are specifically designed for direct placement with simple deployment and fixation into the acutely dissected arch. ${ }^{3,32-34}$

\section{CONCLUSIONS}

Patients who undergo aortic dissection repair are rarely "cured" of their disease. Distal interventions after ascending aortic dissection repair are feasible, but they are associated with early morbidity and subsequent reinterventions. Regularly scheduled follow-up is crucial to prevent delays in reintervention that can affect both operative and longterm survival. In the current era of hybrid and endovascular aortic technology, consideration should be given to extending the initial dissection repair and to early intervention for residual dissection when it can be done safely.

\section{References}

1. Sabik JF, Lytle BW, Blackstone EH, McCarthy PM, Loop FD, Cosgrove DM Long-term effectiveness of operations for ascending aortic dissections. J Thorac Cardiovasc Surg. 2000;119:946-62.

2. Subramanian S, Roselli EE. Thoracic aortic dissection: long-term results of endovascular and open repair. Semin Vasc Surg. 2009;22:61-8.

3. Roselli EE, Rafael A, Soltesz EG, Canale L, Lytle BW. Simplified frozen elephant trunk repair for acute DeBakey type I dissection. J Thorac Cardiovasc Surg. 2013;145:S197-201.

4. Gorlitzer M, Weiss G, Meinhart J, Waldenberger F, Thalmann M, Folkmann S, et al. Fate of the false lumen after combined surgical and endovascular repair treating Stanford type A aortic dissections. Ann Thorac Surg. 2010;89:794-9. 
5. Murzi M, Tiwari KK, Farneti PA, Glauber M. Might type A acute dissection repair with the addition of a frozen elephant trunk improve long-term survival compared to standard repair? Interact Cardiovasc Thorac Surg. 2010; 11:98-102.

6. Uchida N, Shibamura H, Katayama A, Shimada N, Sutoh M, Ishihara H. Operative strategy for acute type A aortic dissection: ascending aortic or hemiarch versus total arch replacement with frozen elephant trunk. Ann Thorac Surg. 2009;87:773-7.

7. Halstead JC, Meier M, Etz C, Spielvogel D, Bodian C, Wurm M, et al. The fate of the distal aorta after repair of acute type A aortic dissection. J Thorac Cardiovasc Surg. 2007; 133:127-35.

8. Zierer A, Voeller RK, Hill KE, Kouchoukos NT, Damiano RJ Jr, Moon MR. Aortic enlargement and late reoperation after repair of acute type A aortic dissection. Ann Thorac Surg. 2007;84:479-86; discussion 86-7.

9. Estrera AL, Miller CC III, Porat E, Mohamed S, Kincade R, Huynh TT, et al. Determinants of early and late outcome for reoperations of the proximal aorta. Ann Thorac Surg. 2004;78:837-45; discussion 45.

10. Pugliese P, Pessotto R, Santini F, Montalbano G, Luciani GB, Mazzucco A. Risk of late reoperations in patients with acute type A aortic dissection: impact of a more radical surgical approach. Eur J Cardiothorac Surg. 1998;13:576-80; discussion 80-1.

11. Mendoza DD, Kochar M, Devereux RB, Basson CT, Min JK, Holmes K, et al. Impact of image analysis methodology on diagnostic and surgical classification of patients with thoracic aortic aneurysms. Ann Thorac Surg. 2011;92:904-12.

12. Breiman L. Bagging predictors. Machine Learning. 1996;24:123-40.

13. Sauerbrei W, Schumacher M. A bootstrap resampling procedure for model building: application to the Cox regression model. Stat Med. 1992;11:2093-109.

14. Nelson W. Graphical analysis of system repair data. J Qual Technol. 1988;20: 24-35.

15. Blackstone EH, Naftel DC, Turner ME Jr. The decomposition of time-varying hazard into phases, each incorporating a separate stream of concomitant information. J Am Stat Assoc. 1986;81:615-24.

16. Andersen PK, Borgan O, Gill RD, Keiding N. Statistical models based on counting processes. New York: Springer-Verlag; 1995. 176-331.

17. Kalbfleisch JD, Prentice RL. The statistical analysis of failure time data. 2nd ed. New York: Wiley; 2002.

18. Rubin DB. Multiple imputation for non-response in surveys. New York: Wiley; 1987.

19. Fattouch K, Sampognaro R, Navarra E, Caruso M, Pisano C, Coppola G, et al. Long-term results after repair of type a acute aortic dissection according to false lumen patency. Ann Thorac Surg. 2009;88:1244-50.

20. Pujara AC, Roselli EE, Hernandez AV, Vargas Abello LM, Burke JM, Svensson LG, et al. Open repair of chronic distal aortic dissection in the endovascular era: implications for disease management. J Thorac Cardiovasc Surg. 2012;144:866-73.

21. Dossche KM, Tan ME, Schepens MA, Morshuis WJ, de la Riviere AB. Twenty-four year experience with reoperations after ascending aortic or aortic root replacement. Eur J Cardiothorac Surg. 1999;16:607-12.

22. Homer-Vanniasinkam S. Surgical site and vascular infections: treatment and prophylaxis. Int J Infect Dis. 2007;11(Suppl 1):S17-22.
23. Hall AJ, Busse EF, McCarville DJ, Burgess JJ. Aortic wall tension as a predictive factor for abdominal aortic aneurysm rupture: improving the selection of patients for abdominal aortic aneurysm repair. Ann Vasc Surg. 2000; $14: 152-7$.

24. Aspelin P, Aubry P, Fransson SG, Strasser R, Willenbrock R, Berg KJ. Nephrotoxic effects in high-risk patients undergoing angiography. $N$ Engl J Med. 2003;348:491-9.

25. Mehran R, Nikolsky E, Kirtane AJ, Caixeta A, Wong SC, Teirstein PS, et al. Ionic low-osmolar versus nonionic iso-osmolar contrast media to obviate worsening nephropathy after angioplasty in chronic renal failure patients: the ICON (ionic versus non-ionic contrast to obviate worsening nephropathy after angioplasty in chronic renal failure patients) study. JACC Cardiovasc Interv. 2009;2:415-21.

26. Svensson LG. The elephant trunk procedure: uses in complex aortic diseases. Curr Opin Cardiol. 2005;20:491-5.

27. Roselli EE, Sepulveda E, Pujara AC, Idrees J, Nowicki E. Distal landing zone open fenestration facilitates endovascular elephant trunk completion and false lumen thrombosis. Ann Thorac Surg. 2011;92:2078-84.

28. Roselli EE, Subramanian S, Sun Z, Idrees J, Nowicki E, Blackstone EH, et al. Endovascular versus open elephant trunk completion for extensive aortic disease. J Thorac Cardiovasc Surg. 2013;146:1408-16; discussion 16-7.

29. Lima B, Roselli EE, Soltesz EG, Johnston DR, Pujara AC, Idrees J, et al. Modified and "reverse" frozen elephant trunk repairs for extensive disease and complications after stent grafting. Ann Thorac Surg. 2012;93:103-9; discussion 9.

30. Bischoff MS, Scheumann J, Brenner RM, Ladage D, Bodian CA, Kleinman G, et al. Staged approach prevents spinal cord injury in hybrid surgicalendovascular thoracoabdominal aortic aneurysm repair: an experimental model. Ann Thorac Surg. 2011;92:138-46; discussion 46.

31. Etz CD, Zoli S, Mueller CS, Bodian CA, Di Luozzo G, Lazala R, et al. Staged repair significantly reduces paraplegia rate after extensive thoracoabdominal aortic aneurysm repair. J Thorac Cardiovasc Surg. 2010;139:1464-72.

32. Ishihara H, Uchida N, Yamasaki C, Sakashita M, Kanou M. Extensive primary repair of the thoracic aorta in Stanford type A acute aortic dissection by means of a synthetic vascular graft with a self-expandable stent. J Thorac Cardiovasc Surg. 2002;123:1035-40.

33. Uchida N, Ishihara H, Shibamura H, Kyo Y, Ozawa M. Midterm results of extensive primary repair of the thoracic aorta by means of total arch replacement with open stent graft placement for an acute type A aortic dissection. J Thorac Cardiovasc Surg. 2006;131:862-7.

34. Sun LZ, Qi RD, Chang Q, Zhu JM, Liu YM, Yu CT, et al. Surgery for acute type A dissection using total arch replacement combined with stented elephant trunk implantation: experience with 107 patients. J Thorac Cardiovasc Surg. 2009; 138:1358-62.

35. Roselli EE. We should replace the aortic arch and more in DeBakey type I dissection-a perspective from the Cleveland Clinic. Ann Cardiothorac Surg. 2013;2:216-21.

36. Song JM, Kim SD, Kim JH, Kim MJ, Kang DH, Seo JB, et al. Long-term predictors of descending aorta aneurysmal change in patients with aortic dissection. J Am Coll Cardiol. 2007;50:799-804. 


\section{APPENDIX E1. VARIABLES CONSIDERED IN MULTIVARIABLE ANALYSES}

\section{Patient-Level Characteristics}

Demography. Age (years), sex, race (black, white). Prior DeBakey I aortic dissection and its repair. Acute/ chronic; characteristics of prior operation (ascending replacement alone, ascending + valve resuspension, supracoronary ascending + aortic valve replacement, Bentall procedure, ascending + root valve sparing); characteristics of prior distal anastomosis (ascending aorta, arch).

\section{Patient and Procedure Characteristics at Time of Reoperations (Used as Time-Varying Covariables in the Time-Related Analysis)}

Demography. Height $(\mathrm{cm})$, weight $(\mathrm{kg})$, body surface area $\left(\mathrm{m}^{2}\right)$, body mass index $\left(\mathrm{kg} \cdot \mathrm{m}^{-2}\right)$.

Characteristics of aneurysm or dissection. Preoperative thoracic aorta maximum diameter, extent of distal dissection (thoracic, abdominal/visceral, ileofemoral).

Preoperative status. New York Heart Association functional class, emergency surgery; heart failure.

Ventricular function. Prior myocardial infarction.

Valve pathology. Aortic valve regurgitation, mitral valve regurgitation, pulmonary valve regurgitation, tricuspid valve regurgitation.

Cardiac comorbidity. Connective tissue disorder, preoperative atrial fibrillation or flutter, complete heart block or pacer, ventricular arrhythmia, endocarditis.

Noncardiac comorbidity. Peripheral arterial disease, carotid disease, hypertension, diabetes, prior stroke, history of smoking, chronic obstructive pulmonary disease, renal dialysis, blood urea nitrogen $\left(\mathrm{mg} \cdot \mathrm{dL}^{-1}\right)$, bilirubin $\left(\mathrm{mg} \cdot \mathrm{dL}^{-1}\right)$, hematocrit $(\%)$, total cholesterol (mg . $\mathrm{dL}^{-1}$ ), high-density lipoprotein cholesterol $\left(\mathrm{mg} \cdot \mathrm{dL}^{-1}\right)$, low-density lipoprotein cholesterol $\left(\mathrm{mg} \cdot \mathrm{dL}^{-1}\right)$, triglycerides $\left(\mathrm{mg} \cdot \mathrm{dL}^{-1}\right)$, creatinine $\left(\mathrm{mg} \cdot \mathrm{dL}^{-1}\right)$, creatinine clearance $\left(\mathrm{mL} \cdot \mathrm{min}^{-1}\right)$, glomerular filtration rate.
Concomitant procedures. Coronary artery bypass grafting, aortic valve surgery, aortic valve replacement, mitral valve surgery, mitral valve repair, number of surgical components. Indication for reoperation. Aneurysmal degeneration, new dissection, symptomatic chronic dissection, rupture, other, infected graft.

Incision detail. Invasiveness (full incision, less invasive, percutaneous).

Procedure performed. Ascending aorta, arch, elephant trunk (first stage, second stage, frozen), descending/ thoracoabdominal aorta (open, endograft-stent), any aortic root, ascending aorta, or arch replacement, descending aorta grafting.

Anastomosis site. Proximal site (before brachiocephalic artery; between left common carotid artery and left subclavian artery; after left subclavian artery), distal site (before brachiocephalic artery; between brachiocephalic artery and left common carotid artery; between left common carotid artery and left subclavian artery; after left subclavian artery; mid-descending; supraceliac; renal/ infrarenal; ileofemoral).

Segmental variables. Extent of aorta replaced/stented, lower/upper aortic anastomosis site indicators, arch alone; descending/thoracoabdominal aorta alone, arch and descending/thoracoabdominal aorta.

Support. Cardiopulmonary bypass, total cardiopulmonary bypass time (min), aortic clamp/balloon occlusion, circulatory arrest, total circulatory arrest time (min), total myocardial ischemic time ( $\mathrm{min}$ ).

Intervals. Date of operation (interval, days from January 1, 1993 to reintervention), interval (y) from initial DeBakey dissection repair to first reoperation, interval (y) between reoperations, interval (y) between DeBakey stage-I repair and each reoperation.

Predischarge computed tomography characteristics. Aortic diameter distal to repair, residual distal dissection (patent false lumen). 

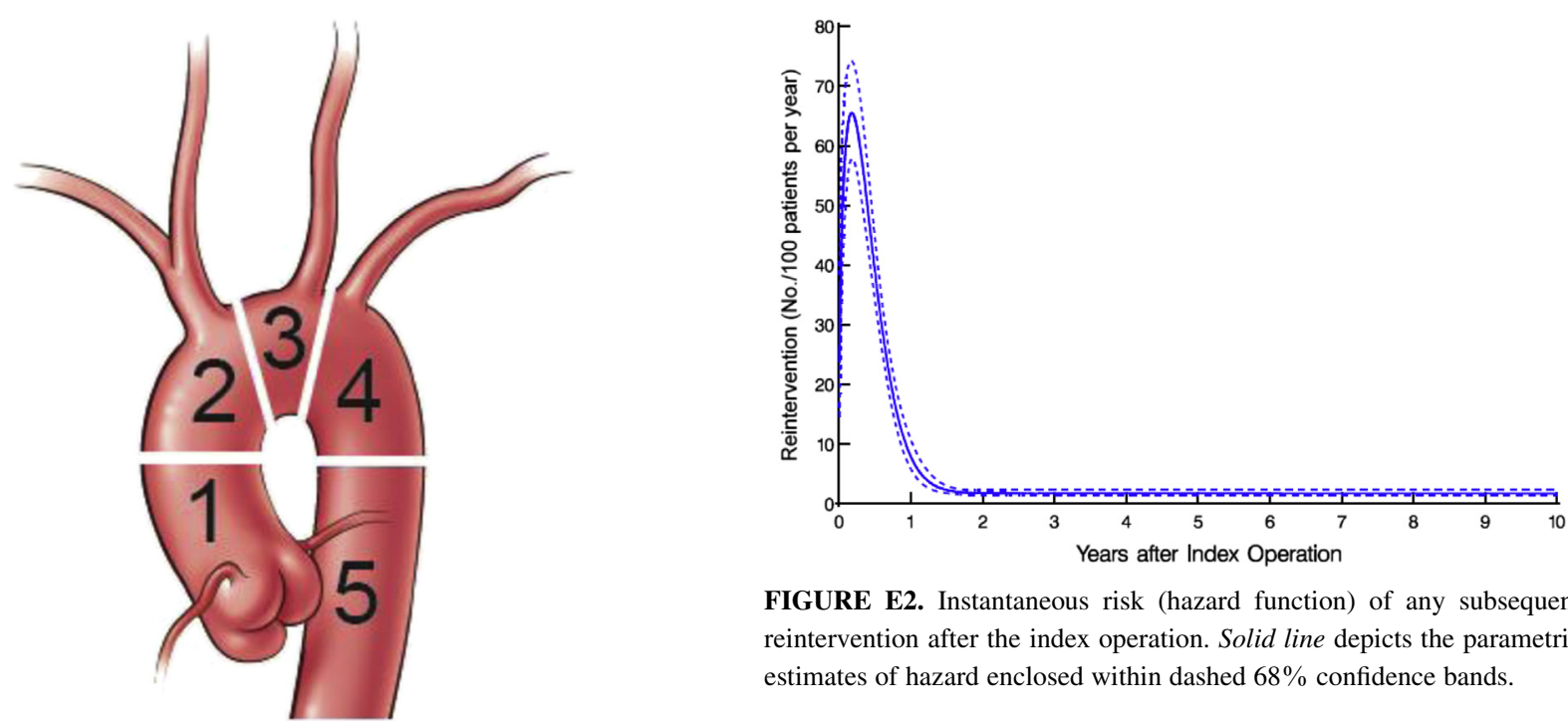

FIGURE E2. Instantaneous risk (hazard function) of any subsequent reintervention after the index operation. Solid line depicts the parametric estimates of hazard enclosed within dashed $68 \%$ confidence bands.

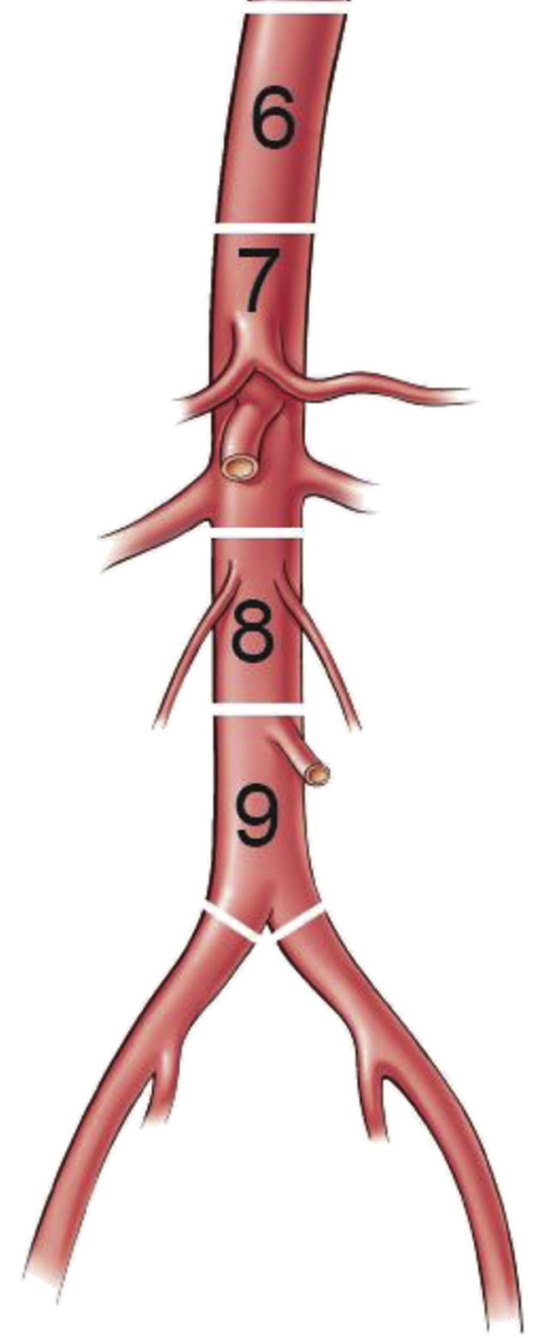

FIGURE E1. Segmental analyses of aorta. Landmarks for each of 9 segments were: (1) brachiocephalic artery, (2) left common carotid artery, (3) left subclavian artery, (4) proximal descending, (5) mid-descending, (6) supraceliac, (7) renal, (8) infrarenal, and (9) ileofemorals.

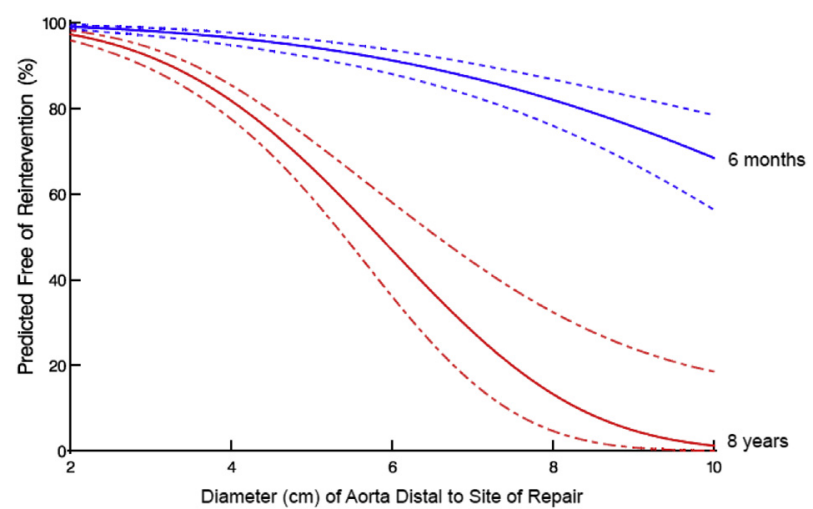

FIGURE E3. Six-month and 8-year freedom from first reintervention according to size of the aorta distal to site of repair. This is a nomogram solved for the multivariable equation for a patient who did not undergo an elephant trunk procedure.

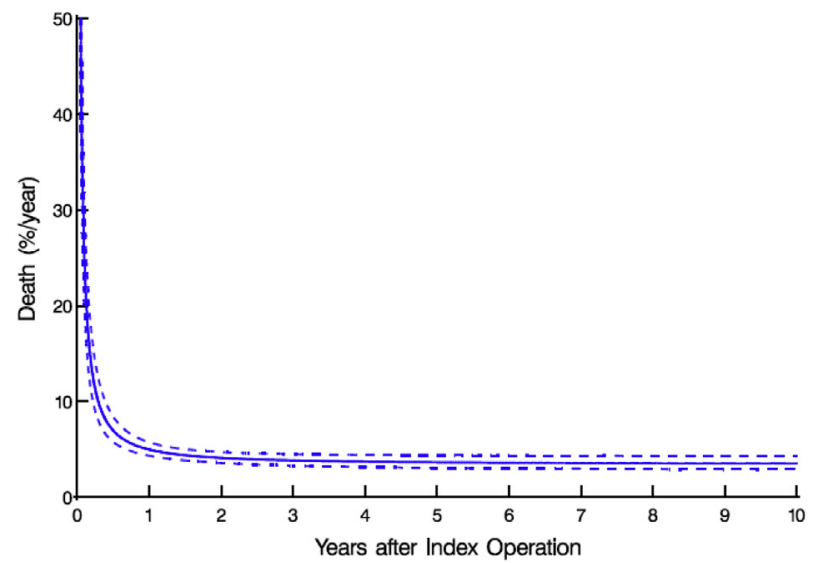

FIGURE E4. Instantaneous risk (hazard function) of death after first reoperation. Solid line represents parametric estimates of hazard enclosed within a dashed $68 \%$ confidence band. 


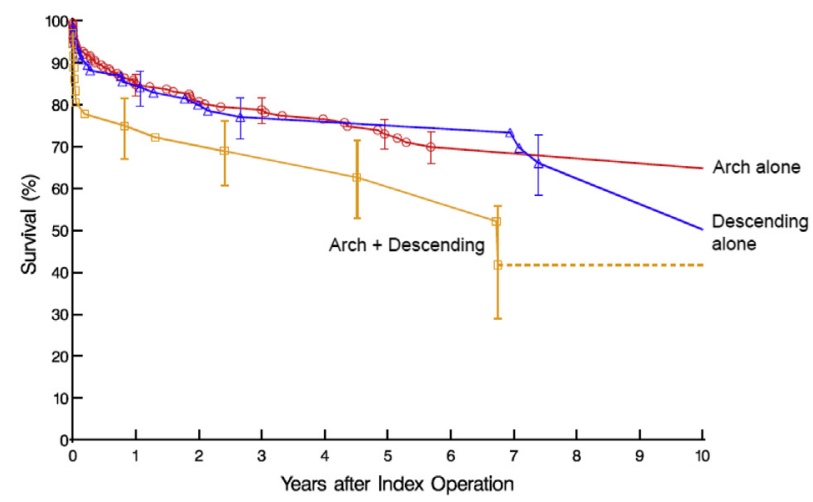

FIGURE E5. Survival after index operation according to site of procedure, demonstrating lower early survival after combined arch and descending aorta procedures. Kaplan-Meier estimates with a symbol at each death; vertical bars represent $68 \%$ confidence limits.

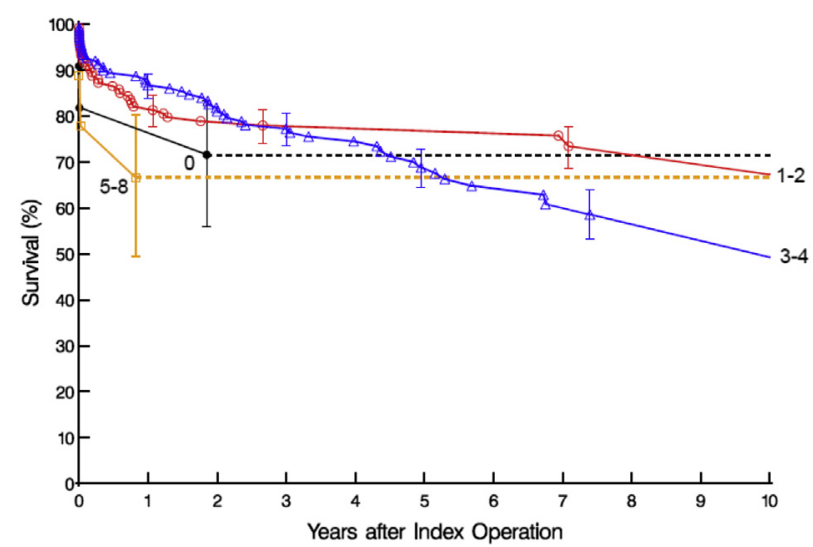

FIGURE E6. Survival after index operation. Each symbol represents a Kaplan-Meier nonparametric estimate with $68 \%$ confidence limits equivalent to \pm 1 standard error.
TABLE E1. Risk factors associated with the in-hospital composite event after any reoperation $(n=429)$

\begin{tabular}{lccc}
\hline \multicolumn{1}{c}{ Factor } & Coefficient $\pm \mathbf{S E}$ & $\boldsymbol{P}$ & $\begin{array}{c}\text { Reliability } \\
(\%)\end{array}$ \\
\hline $\begin{array}{l}\text { More likely } \\
\quad \text { Shorter in height* }\end{array}$ & $-2.6 \pm 1.0$ & .01 & 53 \\
$\quad \begin{array}{l}\text { Indication for reoperation } \\
\quad \text { Aneurysmal degeneration }\end{array}$ & $2.2 \pm 0.77$ & .004 & 58 \\
$\quad \begin{array}{l}\text { Rupture } \\
\text { Less likely }\end{array}$ & $2.2 \pm 0.66$ & .001 & 58 \\
$\quad \begin{array}{l}\text { Distal aortic anastomosis } \\
\text { below celiac artery }\end{array}$ & $-1.3 \pm 0.41$ & .002 & 56 \\
\hline $\begin{array}{l}\text { C-statistic }=0.68 \text {. Composite event includes bleeding, stroke, dialysis, tracheostomy, } \\
\text { and myocardial infarction. Reliability is percentage of times factor appeared in } 500\end{array}$ \\
bootstrap models. SE, Standard error. *(Height/180) ${ }^{2}$, squared transformation.
\end{tabular}

TABLE E2. Risk factors associated with in-hospital death after any reoperation $(n=429)$

\begin{tabular}{|c|c|c|c|}
\hline Factor & Coefficient \pm SE & $\boldsymbol{P}$ & Reliability (\% \\
\hline Infected graft & $2.2 \pm 0.63$ & $<.001$ & 81 \\
\hline $\begin{array}{l}\text { Prior DeBakey dissection } \\
\text { (chronic) }\end{array}$ & $2.7 \pm 0.86$ & .002 & 56 \\
\hline $\begin{array}{l}\text { Arch and descending/ } \\
\text { thoracoabdominal procedure }\end{array}$ & $2.9 \pm 0.59$ & $<.001$ & 91 \\
\hline $\begin{array}{l}\text { Smaller segmental value (extent } \\
\text { of aorta replaced or stented)* }\end{array}$ & $-1.2 \pm 0.60$ & .04 & 73 \\
\hline Concomitant CABG & $1.3 \pm 0.58$ & .02 & 48 \\
\hline
\end{tabular}

C-statistic $=0.84$. Reliability is percentage of times factor appeared in 500 bootstrap models. SE, Standard error; $C A B G$, coronary artery bypass grafting. * $\log ($ extent of aorta replaced or stented), logarithmic transformation. 